\title{
Series Bosch System Development
}

\author{
Morgan B. Abney ${ }^{1}$, Christopher Evans ${ }^{2}$, and Matt Mansell ${ }^{3}$ \\ NASA Marshall Space Flight Center, Huntsville, AL 35812 \\ and \\ Michael Swickrath ${ }^{4}$ \\ NASA Johnson Space Center, Houston, TX 77058
}

\begin{abstract}
State-of-the-art (SOA) carbon dioxide $\left(\mathrm{CO}_{2}\right)$ reduction technology for the International Space Station produces methane as a byproduct. This methane is subsequently vented overboard. The associated loss of hydrogen ultimately reduces the mass of oxygen that can be recovered from $\mathrm{CO}_{2}$ in a closed-loop life support system. As an alternative to $\mathrm{SOA} \mathrm{CO}_{2}$ reduction technology, NASA is exploring a Series-Bosch system capable of reducing $\mathrm{CO}_{2}$ with hydrogen to form water and solid carbon. This results in $100 \%$ theoretical recovery of oxygen from metabolic $\mathrm{CO}_{2}$. In the past, Bosch-based technology did not trade favorably against SOA technology due to a high power demand, low reaction efficiencies, concerns with carbon containment, and large resupply requirements necessary to replace expended catalyst cartridges. An alternative approach to Bosch technology, labeled "Series-Bosch," employs a new system design with optimized multi-stage reactors and a membrane-based separation and recycle capability. Multi-physics modeling of the first stage reactor, along with chemical process modeling of the integrated system, has resulted in a design with potential to trade significantly better than previous Bosch technology. The modeling process and resulting system architecture selection are discussed.
\end{abstract}

\section{Nomenclature}

$\begin{array}{ll}\text { ACM } & =\text { Aspen Custom Modeler }{ }^{\circledR} \\ \text { ALSSAT } & =\text { Advanced Life Support Sizing and Analysis Tool } \\ \mathrm{AR} & =\text { Atmosphere revitalization } \\ \mathrm{CFr} & =\text { Carbon formation reactor } \\ \mathrm{CM} & =\text { Crew member } \\ \mathrm{CO}_{2} & =\text { Carbon dioxide } \\ c_{P} & =\text { Power equivalency for ESM analysis, }[\mathrm{kg} / \mathrm{kW}] \\ c_{Q} & =\text { Cooling equivalency for ESM analysis, }[\mathrm{kg} / \mathrm{kW}] \\ c_{t} & =\text { Crew-time equivalency for ESM analysis, }[\mathrm{kg} / \mathrm{CM}-\mathrm{hr}] \\ c_{V} & =\text { Volume equivalency for ESM analysis, }\left[\mathrm{kg} / \mathrm{m}^{3}\right] \\ \mathrm{ESM} & =\text { Equivalent system mass } \\ \mathrm{EVA} & =\text { Extra-vehicular activity } \\ \mathrm{H}_{2} & =\text { Hydrogen } \\ \mathrm{ISS} & =\text { International Space Station } \\ \mathrm{LSS} & =\text { Life support system } \\ \mathrm{M} & =\text { Mass, }[\mathrm{kg}] \\ \mathrm{MSFC} & =\text { Marshall Space Flight Center } \\ \mathrm{O}_{2} & =\text { Oxygen } \\ \mathrm{RWGS} & =\text { Reverse Water-Gas Shift }\end{array}$

${ }_{1}^{1}$ Aerospace Engineer, ECLSS Development Branch, ES62, AIAA Member.

${ }^{2}$ Aerospace Technologist, Thermal Analysis and Control Branch, EV34, Non-Member.

${ }^{3}$ Aerospace Engineer, ECLSS Development Branch, ES62, AIAA Member.

${ }^{4}$ Analyst, Crew and Thermal Systems Division, 2101 NASA Parkway/EC2, Houston, TX 77058, AIAA Member. 
SLPM = Standard liters per minute

SOA $=$ State-of-the-art

\section{Introduction}

$\mathrm{H}$ istorically, NASA has designed and developed hardware to meet specific mission objectives, constrained to a large extent by the destination, and therefore, the duration of the mission. NASA is now looking at a future that may include any number of destinations such as near earth objects, Lagrange points, and Lunar or Martian surface missions, among others. Although there is some level of mission ambiguity, each of these missions will require reliable and robust life support systems capable of maximizing resource recovery and recycling.

For Atmosphere Revitalization (AR) systems, state-of-the-art (SOA) technology on the International Space Station (ISS) is capable of 50\% theoretical recovery of oxygen $\left(\mathrm{O}_{2}\right)$ from metabolic carbon dioxide $\left(\mathrm{CO}_{2}\right)$. Testing of development-level hardware for the SOA system suggests that only about $42 \% \mathrm{O}_{2}$ recovery is actually achieved. ${ }^{1}$ This results in a loss of over $153 \mathrm{~kg} \mathrm{O}_{2}$ per crew member (CM) per year. For a crew of four, and assuming $\$ 55,000$ to launch one kilogram of mass to ISS ( $\$ 25,000$ per pound), this translates to annual launch costs of over $\$ 37.8 \mathrm{M}$, when resupplied as water. For missions beyond low earth orbit, this cost will be significantly greater, making frequent resupply missions prohibitive. As an alternative to SOA technology for long-duration missions, NASA is investigating Bosch-based systems capable of $100 \%$ theoretical recovery of $\mathrm{O}_{2}$ from metabolic $\mathrm{CO}_{2}$.

In recent years, efforts have been ongoing at NASA's Marshall Space Flight Center (MSFC) to redesign a Bosch-based $\mathrm{CO}_{2}$ reduction system. Bosch-based systems have been a part of the NASA $\mathrm{CO}_{2}$ reduction portfolio since the early 1960's. However, engineering challenges, most notably the large resupply requirements, carbon containment and handling difficulties, and low single-pass efficiencies, have resulted in poor comparative performance with respect to alternatives with lower recovery performance (e.g. SOA with only $\sim 42 \% \mathrm{O}_{2}$ recovery from metabolic $\left.\mathrm{CO}_{2}\right) .{ }^{2}$ In an effort to address these challenges, a new approach to Bosch-based $\mathrm{CO}_{2}$ reduction has been proposed. ${ }^{3}$ In short, this approach seeks to separate the two steps in Bosch-based $\mathrm{O}_{2}$ recovery such that each step can be optimized for maximum performance and provide alternative options for carbon collection/containment.

The first step in Bosch-based $\mathrm{O}_{2}$ recovery is the Reverse Water-Gas Shift (RWGS) reaction as shown in equation 1 below. The second step is the carbon formation step comprised of two reactions occurring in parallel as shown in equations 2 and 3 below.

$$
\begin{aligned}
\mathrm{CO}_{2}+\mathrm{H}_{2} & \leftrightarrow \mathrm{CO}+\mathrm{H}_{2} \mathrm{O} \\
\mathrm{CO}+\mathrm{H}_{2} & \leftrightarrow \mathrm{C}+\mathrm{H}_{2} \mathrm{O} \\
2 \mathrm{CO} & \leftrightarrow \mathrm{CO}_{2}+\mathrm{C}
\end{aligned}
$$

The RWGS is an endothermic reaction that is kinetically and thermodynamically favorable at high temperatures. The two carbon formation reactions are exothermic. These reactions are kinetically favorable at high temperatures but thermodynamically favorable at lower temperatures. Thus, for an S-Bosch system, a RWGS reactor can be optimized to operate at high temperatures on a relatively small catalyst bed. A Carbon Formation reactor (CFr) can be optimized to operate at a high temperature at the inlet to favor kinetics and a lower temperature at the outlet to favor thermodynamics. Additionally, the CFr can be designed such that carbon handling/containment is much less crew-intensive than previous designs, and may possibly avoid thermal cycling. The two-staged series approach to Bosch that provides optimization at both steps in the process will theoretically result in $50-70 \%$ single-pass efficiencies, compared to 5-8\% from traditional Bosch.

Recent efforts in S-Bosch development have focused on system and sub-system design. Aspen modeling of a preliminary system architecture has provided critical information for a proposed brassboard S-Bosch. Similarly, COMSOL modeling of a RWGS reactor has led to the design of a 4-crew member sized sub-system. Both of these efforts are detailed below.

\section{Series-Bosch System Architecture Model Development}

In an attempt to facilitate ongoing hardware design efforts, modeling of both system level architecture and the RWGS sub-system were undertaken. The methodology for each effort is described in detail below.

\section{A. Series-Bosch System Architecture Model Development}

In order to begin understanding performance in the context of a system, a Series-Bosch model was developed. The model provides the capability to explore how system temperature and pressure influence the equilibrium composition. In addition, the system model was constructed in a modular format with specific subcomponent models 
so that subcomponents can be easily added, removed, or re-located to explore design impacts. The following section serves to elaborate on sub-component models as well as demonstrate some results from the model.

The model was constructed in the Aspen Custom Modeler® (ACM) software package (Aspen Tech, Inc.; Burlington, MA). The current schematic representation is illustrated in Error! Reference source not found.. As is evident in the illustration, a number of sub-components exist within the system including gas source tanks for $\mathrm{CO}_{2}$ and $\mathrm{H}_{2}$ introduction $\left(\mathrm{CO}_{2}\right.$ and $\mathrm{H}_{2} \mathrm{O}$ ), gas reactors (RWGS and CFR), stream mixers (Mixer1 and Mixer2), regenerative heat exchangers (RegenHX1 and RegenHX2), heaters (Heater1 - Heater4), a compressor, a condensing heat exchanger (CHX), a pre-compression cooling unit (PreCool), a stream splitter, and membrane separators $\left(\mathrm{CO} 2 \mathrm{Membrane}\right.$ and $\left.\mathrm{MembraneH}_{2}\right)$. Each subcomponent represented in Figure 1Figure 1 has an associated model. The models for separate subcomponents vary in fidelity and will be discussed in the following sections.

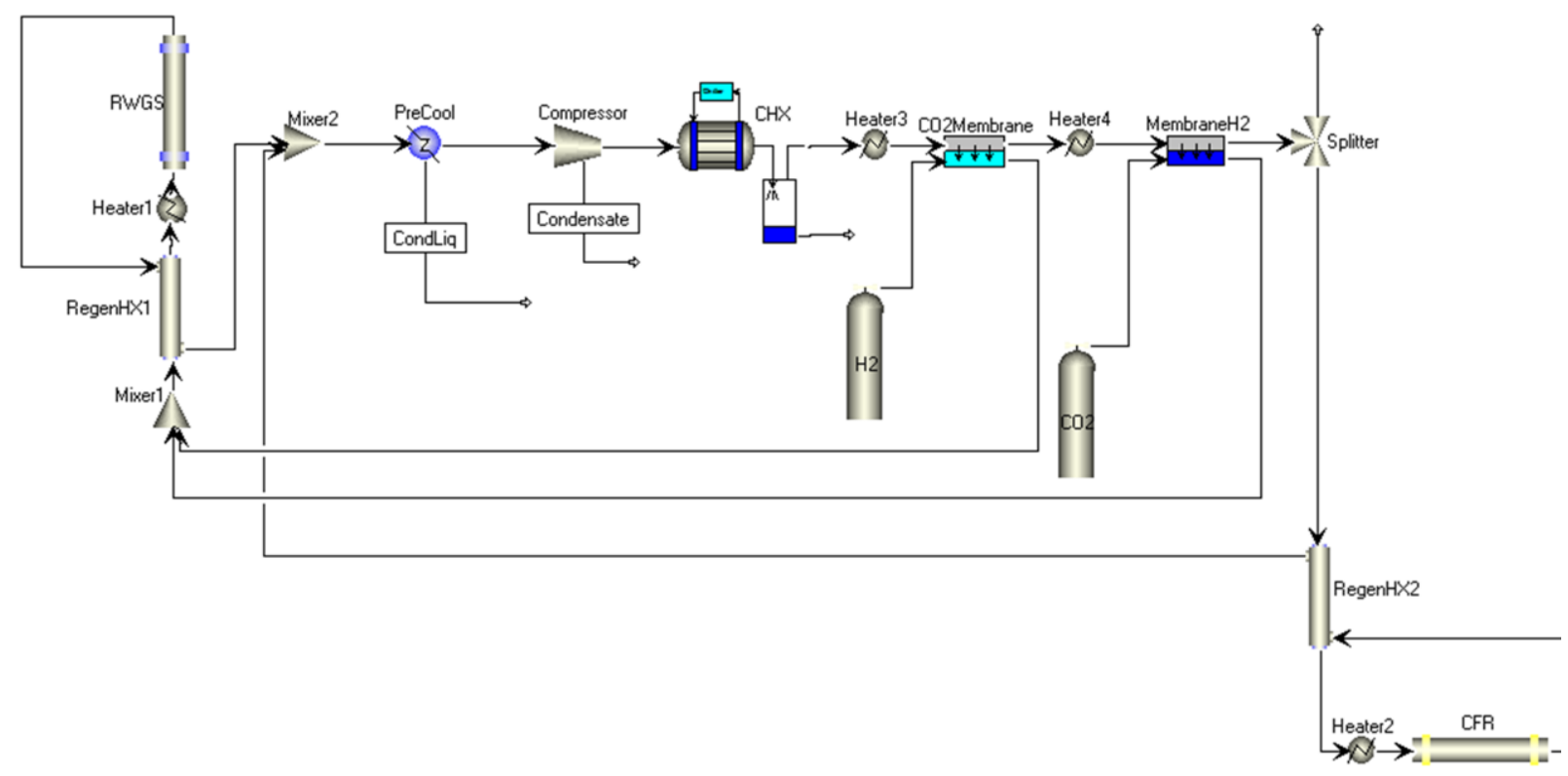

Figure 1. Schematic representation of S-Bosch reactor system as constructed in Aspen Custom Modeler® software package.

\section{Series-Bosch Reactor Models}

The Series-Bosch system is being deliberately designed to control the rate and location of coke formation thereby reducing reactor maintenance and consumables associated with catalyst replacement. Toward this objective, the Bosch process is separated into a series reactor system with each reactor operating at a temperature and pressure more favorable for the generation of specific products. In particular, six separate reactions are believed to occur during the Bosch process.

Reverse water-gas shift:

$$
\mathrm{CO}_{2}+\mathrm{H}_{2} \rightleftharpoons \mathrm{CO}+\mathrm{H}_{2} \mathrm{O}
$$

Carbon dioxide methanation:

$$
\mathrm{CO}_{2}+4 \mathrm{H}_{2} \rightleftharpoons \mathrm{CH}_{4}+2 \mathrm{H}_{2} \mathrm{O}
$$

Carbon monoxide hydrogenation:

$$
\mathrm{CO}+\mathrm{H}_{2} \rightleftharpoons \mathrm{C}(\mathrm{s})+\mathrm{H}_{2} \mathrm{O}
$$

Carbon monoxide methanation:

$$
\mathrm{CO}+3 \mathrm{H}_{2} \rightleftharpoons \mathrm{CH}_{4}+\mathrm{H}_{2} \mathrm{O}
$$

Carbon methanation:

$$
\mathrm{C}(\mathrm{s})+2 \mathrm{H}_{2} \rightleftharpoons \mathrm{CH}_{4}
$$

Boudouard reaction:

$$
2 \mathrm{CO} \rightleftharpoons \mathrm{C}(\mathrm{s})+\mathrm{CO}_{2}
$$


Each equilibrium reaction has an associated equilibrium coefficient that can be manipulated through reactor temperature and pressure to favor the desired products. In particular, the first reactor is operated at a higher temperature and lower pressure to encourage the RWGS reaction to proceed. The second reactor is operated at a higher pressure and lower temperature favoring carbon monoxide consumption.

To model the influence of temperature and pressure, equilibrium coefficients are calculated from a first principles approach. The temperature dependence on equilibrium is captured through the formal definition of the equilibrium coefficient, $K_{a}$, expressed with respect to species activity, $a_{i}$.

$$
\ln K_{a}=\ln \prod_{i=1}^{n} a_{i}^{v_{i}}=-\frac{\Delta G_{\mathrm{Rxn}}^{\mathrm{o}}}{R T}
$$

In Eq. (7), $v_{i}$ represents the stoichiometric coefficient of species $i=1, \ldots, n, R$ is the universal gas constant $(8.314472 \mathrm{~J} / \mathrm{mol}-\mathrm{K})$, and $\Delta G_{\mathrm{Rxn}}^{\mathrm{o}}$ is the Gibbs free energy of reaction at standard temperature and pressure $\left(0^{\circ} \mathrm{C}\right.$ and 1.01325 bar). Through the definition of the free energy of reaction and enthalpy of reaction, $\Delta H_{\mathrm{Rxn}}(T)$, Eq. (7) is related to free energy $\Delta G_{f, i}^{o}$ and heat of formation, $\Delta H_{f, i}^{o}$, for each species.

$$
\frac{d \ln K_{a}}{d T}=-\frac{1}{R} \frac{d}{d T}\left[\frac{\sum_{i} v_{i} \Delta G_{f, i}^{\mathrm{o}}}{T}\right]=\frac{1}{R T^{2}} \sum_{i} v_{i} \Delta H_{f, i}^{\mathrm{o}}=\frac{\Delta H_{\mathrm{Rxn}}(T)}{R T^{2}}
$$

The heat of reaction at elevated temperatures is calculated with the reactive change in mixture constant pressure specific heat, $\Delta C_{p}=\sum_{i} v_{i} C_{p, i}$. The component constant pressure specific heat values were determined from polynomial fits to experimental data annotated in elsewhere. ${ }^{4}$

$$
\Delta H_{\mathrm{Rxn}}(T)=\Delta H_{\mathrm{Rxn}}^{\mathrm{o}}+\int_{T_{\mathrm{o}}}^{T} \Delta C_{p}\left(T^{\prime}\right) d T^{\prime}
$$

With substitution of Eq. (9) into Eq. (8) and subsequent integration, the expression used in the model for the equilibrium coefficient calculation at elevated temperatures.

$$
\ln \left[\frac{K_{a}(T)}{K_{a}\left(T_{\mathrm{o}}\right)}\right]=-\frac{\Delta H_{\mathrm{Rxn}}}{R}\left[\frac{1}{T}-\frac{1}{T_{\mathrm{o}}}\right]
$$

Assuming ideality since reactor pressures are far beneath the component critical pressures, the equilibrium coefficient expressed in terms of component activity is related to pressure according to the following relationship. Finally, Eq. (11) provides a quantitative value for the equilibrium coefficient as a function of temperature, pressure, and component molar fraction $y_{i}$.

$$
K_{a}=\prod_{i=1}^{n}\left(y_{i} \frac{P}{P_{\mathrm{o}}}\right)^{v_{i}}
$$

As suggested by Eq. (11), the pressure can have a significant influence on the reactions that do not have gas-phase stoichiometric coefficients that sum to zero.

For the calculation of equilibrium composition, an extent of reaction analysis is employed. ${ }^{5-6}$ Specifically, the final molar fraction, $y_{i}$, is determined from initial molar fraction, $y_{i, 0}$, and the extent of reaction, $\xi_{j}$, for reaction $j=1, \ldots, m$.

$$
y_{i}=y_{i, \mathrm{o}}+\sum_{j=1}^{m} v_{i, j} \xi_{j}
$$

Equations (11) and (12) provide relationships for the final composition of all species and the extent of reaction to occur to achieve these compositions as a function of temperature and pressure. The equations were solved simultaneously with the ACM software package.

$$
4
$$

American Institute of Aeronautics and Astronautics 


\section{Series-Bosch Regenerative Heat Exchanger and Heater Models}

A steady-state heat exchanger model was constructed for the Series-Bosch system. With limited data on the actual heat exchanger to be employed for testing, specifications of which will likely follow from the analytical results, a number of transfer units (NTU) analysis was employed. In this analysis, the number of transfer units has the following definition.

$$
\mathrm{NTU}=\frac{U A}{\min \left(C_{p, c} \dot{N}_{c}, C_{p, c} \dot{N}_{h}\right)}
$$

The denominator represents the minimum value of the cold $(c)$ and hot $(h)$ molar flow rates $(\dot{N})$ multiplied by the molar specific heat of the mixture. It is necessary to take the minimum of the product of these terms in order to capture the maximum physically achievable heat transfer that can occur between the working fluids. The quantity $U A$ is the overall heat transfer coefficient multiplied by the area available for heat transfer. This quantity is not known at this point. Instead, the number of transfer units is fixed to a large number (10-50) and a value for $U A$ arises that would need to be achieved in practice in order to attain high heat transfer efficiencies. This value can subsequently be used in evaluating existing commercial off-the-shelf (COTS) heat exchangers for application in the Series-Bosch reactor system.

In addition to Eq. (13), the steady-state energy balance over the regenerative heat exchangers is as follows.

$$
\begin{gathered}
Q=C_{p, c} \dot{N}_{c}\left(T_{f, c}-T_{\mathrm{o}, c}\right) \\
Q=-C_{p, h} \dot{N}_{h}\left(T_{f, h}-T_{\mathrm{o}, h}\right) \\
Q=\frac{U A\left[\left(T_{f, h}-T_{\mathrm{o}, c}\right)-\left(T_{\mathrm{o}, h}-T_{f, c}\right)\right]}{\ln \left[\frac{\left(T_{f, h}-T_{\mathrm{o}, c}\right)}{\left(T_{\mathrm{o}, h}-T_{f, c}\right)}\right]}
\end{gathered}
$$

Consequently, equations (13-16) provide all data required for the calculation of hot and cold outlet temperature (denoted by $f$ for "final" temperature) as well as the heat exchanger requirements to attain the associated temperatures as a function of $U A$.

In the case of the heater models, desired outlet temperatures are set while inlet temperatures are calculated within the model. Consequently, the heat load to achieve the temperatures is calculated similar to the previous analysis $\left(Q=C_{p} \dot{N}\left(T_{f}-T_{\mathrm{o}}\right)\right)$.

\section{Condensing Heat Exchanger Model}

The condensing heat exchangers ( $\mathrm{CHX}$ and PreCool in Figure 1) were modeled similar to the heaters where a cooling requirement is calculated based on the desired outlet temperature (assumed to be $50{ }^{\circ} \mathrm{F}$ which slightly exceeds the temperature of cooling water on ISS). Consequently, a heat rejection requirement is determined to cool the gas to the desired temperature for subsequent chiller sizing. Moreover, an additional calculation is performed to assess the inlet partial pressure of water vapor versus the vapor pressure of water. Water vapor pressure was calculated with the Antoine equation. The moles of water associated with the excess partial pressure of water over vapor pressure are presumed to condense and the molar flow rate of both water vapor and water are subsequently calculated.

\section{Stream Mixer Model}

Stream mixers are modeled as an adiabatic mixing process within ACM relying on built-in properties calculations. Within ACM, the streams are allowed to mix and then a check is performed to assess whether any materials exist under conditions favorable for condensation. If condensation appears favorable, ACM determines the component partitioning according to the thermodynamics properties of the system. For this analysis, the PengRobinson equation of state has been applied for thermodynamic property calculations. 


\section{Compressor Model}

Gas compression is treated as a polytropic process in which the outlet temperature of the compressor is dictated by the ratio of outlet to inlet pressures.

$$
T_{f}=T_{\mathrm{o}}\left(\frac{P_{f}}{P_{\mathrm{o}}}\right)^{\frac{n-1}{n}}
$$

In Eq. (17), the parameter $n$ is the polytropic expansion index characteristic of the compressor. Two limiting cases exist bounding the expected temperature range. Isothermal compression occurs when $n=1$. Conversely, adiabatic compression occurs when the polytropic index is equivalent to the isentropic expansion factor for the gas, $n=\gamma$ $\left(\gamma=C_{p} /\left(C_{p}-R\right) \approx 1.38\right.$ for air at standard temperature and pressure $)$.

In the adiabatic case, compression results in a significant temperature rise. The compressor for the Series-Bosch system is a Dia-Vac® R1525700-100 (Air Dimensions, Inc.; Deerfield Beach, FL). While the exact polytropic exponent for this custom compressor is not known, the temperature rise observed during compression experiments in the laboratory seem to indicate this process is much closer to adiabatic. Consequently, the model currently assumes the compression process is adiabatic. When modeled under this assumption, temperatures approach levels that pose a threat to the compressor diaphragm material if the gas is not cooled to threshold levels prior to compression. The advantage of the system model is that it provides the means to explore cooling requirements in detail from a system context. Consequently, the upfront analytical efforts are serving to tailor system design to the hardware that will be used during the experimental investigation.

\section{Membrane Models}

Currently, spiral-wound membrane separator systems are under consideration from Membrane Technology \& Research, Inc. (Menlo Park, CA). Data such as membrane permeabilities, component selectivities, and membrane activation energies are not known due to their proprietary nature. Consequently, a high fidelity membrane model does not exist. As a placeholder until experimental characterization can yield this data, the $\mathrm{CO}_{2}$ membrane is presumed to achieve $80 \%$ recovery while the $\mathrm{H}_{2}$ membrane assumes $60 \%$ recovery. These assumptions were suggested by the vendor as reasonable approximations while the custom membrane separators are being fabricated.

\section{B. Reverse Water-Gas Shift Sub-System Model Development}

Computational models of the RWGS reactor were developed using COMSOL 4.1. The models were designed to capture the key features of the experimental setup while also allowing simulations of a larger-scale system. The computational geometry is shown in Figure 2. For this effort, the system was modeled in two dimensions with symmetry about the reactor axis $(\mathrm{r}=0)$. The geometry included five entities: the tube interior, the porous catalyst (at the center of the tube), two insulating disks of porous quartz batting (one on either end of the catalyst), and the tube wall. Points along the length of the tube were marked to identify the boundaries of the heated furnace, the insulation, etc. (e.g. pt7, pt10, etc). Properties of the porous materials were obtained from the manufacturer and from laboratory tests. The catalyst was modeled as porous nickel with a void fraction of 0.972 and permeability of $6.65 \mathrm{e}^{-10} \mathrm{~m}^{2}$. The insulation disks were modeled as porous quartz with a void fraction of 0.9 and a permeability of $1.42 \mathrm{e}^{-10} \mathrm{~m}^{2}$. The tube wall was modeled as solid quartz. The inlet flow consisted of a gaseous mixture of carbon dioxide and hydrogen, which entered well-mixed.

Three COMSOL physics modules were used in this model: "Free and Porous Media Flow" for the fluid mechanics, "Heat Transfer in Porous Media" for heat transfer, and "Transport of Dilute Species" for chemistry. Fluid behavior was modeled as laminar flow with no slip at the wall. The fluid enters the system with a fully developed laminar velocity profile. Several modes of heat transfer were included: conduction within the solid tube wall and porous materials,

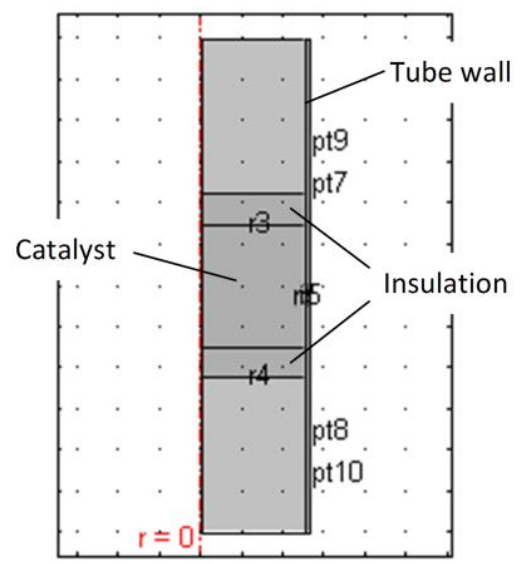

Figure 2. RWGS reactor computational geometry. Points on the outer wall mark the boundaries of the heated furnace area and insulation. 
convection within the fluid stream, free convection with the hot furnace and cool ambient air at the outer surface of the tube, and radiation exchange with the furnace and ambient environment at the outer surface of the tube (though radiation effects were found to be very minor). Chemical reactions, which occur in the catalyst region, were modeled as one-step reversible Arrhenius reactions.

\section{Results and Discussion}

Aspen and COMSOL modeling were conducted to facilitate the design of a brassboard S-Bosch system. The results of these modeling efforts are detailed below.

\section{A. Series-Bosch System Architecture Model Results}

Subcomponent models for the hardware comprising the Series-Bosch process have been developed in an effort to optimize performance from a system context. Consequently, a wide variety of operational scenarios can be rapidly explored lending insight into expected system performance under a variety of conditions. This section presents some model verification experiments as well as expected results for various pressures and temperatures not explored in the laboratory.

\section{Reverse Water-Gas Shift Reactor Verification}

A comprehensive reactive-flow computational fluid dynamics analysis has been performed for the reverse watergas shift reactor. The analysis indicates equilibrium outlet concentrations can be attained at the temperature and pressure under consideration so long as the reactor dimensions are chosen appropriately. From the perspective of the system model, this suggests the equilibrium analysis described in the methodology is appropriate.

As a verification of the equilibrium reactor model, simulation results were compared against experimental data previously collected at MSFC. In particular, results were collected for a sub-scale reactor with approximately 10.1

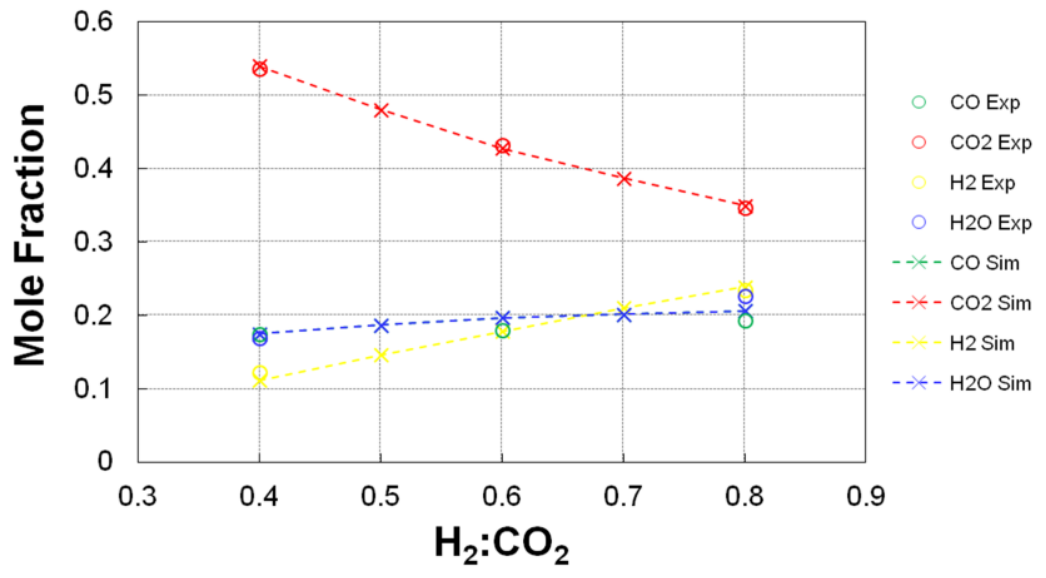

Figure 3. Experimental verification of the Series-Bosch reverse water-gas shift reactor model. Results were collected in a sub-scale reactor with a 1.81 " ID reactor with 4" of catalyst. The flow rate for the experiment was 0.180 SLPM with a reactor temperature of $1200{ }^{\circ} \mathrm{F}\left(650{ }^{\circ} \mathrm{C}\right)$ at a pressure of 14.7 PSIA (1.01325 bar). $\mathrm{cm}$ (4 inches) of catalyst packed in a tube of $4.6 \mathrm{~cm}$ (1.81 inches) ID. The reactor was heated to $650{ }^{\circ} \mathrm{C}(1200$ $\left.{ }^{\circ} \mathrm{F}\right)$ with a flow rate of 0.180 standard liters per minute (SLPM). Hydrogen to carbon dioxide molar ratio was varied from 0.4 to 0.8 $\mathrm{H}_{2}: \mathrm{CO}_{2}$. Outlet composition was assessed via micro-gas chromatography. A comparison between experimental and model results is illustrated in Figure 3.

As demonstrated in Figure 3, model and experimental results are in good agreement. Moreover, as the $\mathrm{H}_{2}: \mathrm{CO}_{2}$ ratio increases $\mathrm{CO}_{2}$ concentration is dramatically reduced. Conversely, with an increase in the ratio of $\mathrm{H}_{2}: \mathrm{CO}_{2}$, water concentration tends to increase although not as significantly as $\mathrm{CO}_{2}$ decreases which indicates the reactions in Eq. (2) through Eq. (6) do have an impact on composition. The results from this analysis are encouraging with respect to the predictive capability of the model to simulate the chemistry in the Series-Bosch system RWGS reactor. The CFr model is constructed through a similar analysis. However, the data for model verification has not been collected at this point. Until that data is acquired, it is presumed that the analytical approach is correct although any data generated by the model is still considered preliminary until properly verified.

\section{Feed-ratio, Temperature, and Pressure Parametric Analyses}

With experimental data verifying the approach to analyzing the steady-state reaction equilibrium, the system model now provides a means to parametrically analyze the system for optimal operating specifications. Eq. (10) and (11) suggest that reactor temperatures and pressures are important in determining equilibrium composition. 
Moreover, the Bosch reaction requires two moles of hydrogen to convert a mole of carbon dioxide to products. According to this stoichiometry, it is also apparent that the $\mathrm{H}_{2}: \mathrm{CO}_{2}$ molar feed ratio also dictates steady-state $\mathrm{CO}_{2}$ conversion. As a result, it was determined that a parametric analysis should be performed on the temperature and pressure of both reactors as well as the feed ratio.

A full-factorial parametric analysis was performed in this investigation for five separate parameters: (1) temperature of the RWGS reactor, (2) pressure of the RWGS reactor, (3) temperature of the CFr, (4) pressure of the $\mathrm{CFr}$, and (5) molar feed ratio of $\mathrm{H}_{2}: \mathrm{CO}_{2}$. It was previously determined that lower pressures favor completion of the RWGS reaction while higher pressures were optimal for the reactions relevant to the CFr. In the factorial analysis, pressure was varied across 4 levels (0.172-0.276 bar (2.5-4.0 PSIA) for the RWGS and 0.483-0.689 bar (7.0-10.0 PSIA) for the CFr). The numerical stability for the reactor system was found to be poor when large perturbations in temperature were forced on the reactors presumably due to the orders of magnitude the equilibrium coefficients vary even across narrow temperature ranges. For the factorial analysis, this means the temperature dependence needed to be assessed across many more levels than pressure. Consequently, 12 levels were chosen since it was experimentally determined to maximize stability while balancing computational costs. For the analysis, temperatures of $625-675{ }^{\circ} \mathrm{C}$ were chosen for the RWGS and $475-525{ }^{\circ} \mathrm{C}$ for the CFr discretized to twelve nodes. For feed ratio, stoichiometry suggests that of a ratio of $\mathrm{H}_{2}: \mathrm{CO}_{2}$ of 2 is optimal. In reality, the Bosch reaction does not proceed according to a the idealized overall equation but instead proceeds according to the reactions represented in Eq. (1-6) to varying degrees of completion giving rise to the observed equilibrium composition. Consequently, 2 may not be the optimal molar feed ratio and this parameter was varied from 1 to 2 to 3 .

Based on the factorial analysis number of factors (5) and levels (4 levels for 2 pressure settings; 12 levels for 2 temperature settings; 3 levels for molar feed ratio), a total of 6,912 calculations were involved in the analysis. Moreover, uniformly distributed random noise was added to the temperature and pressure settings to increase variety in the data for the purposes of subsequent multivariate regression. For the analysis, the uniformly distributed noise was bounded by \pm 0.003 bar ( \pm 0.05 PSIA) and $\pm 0.5{ }^{\circ} \mathrm{C}$ for the pressure and temperature settings. Results for this analysis are demonstrated in Figure 4. After performing the calculations, the data was regressed to develop a model

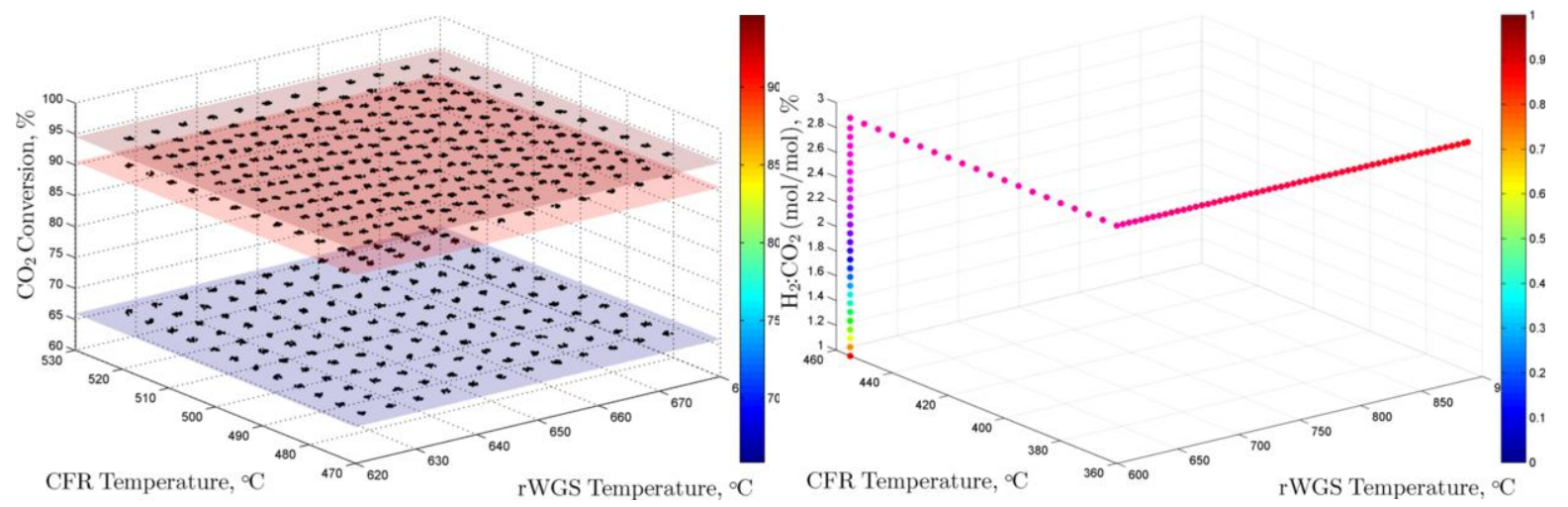

Figure 4. Left: Combinatorial investigation for Series Bosch Reactor System. Surface plots generated from multi-variate regression on feed ratio, temperature and pressure of the reverse water-gas shift (RWGS) reactor, and temperature and pressure of the RWGS reactor, and temperature and pressure of the $C F r$. Right: Incremental calculations for the $\mathbf{S}$-Bosch reactor system to optimize $\mathrm{CO}_{2}$ conversion as a function of reactor temperatures and feed ratio. Marker color is associated with the percent conversion of $\mathrm{CO}_{2}$.

relating feed ratio and temperatures and pressures to conversion. Regression processing resulted in p-values for all coefficients. With a p-value of less than 0.05 , the null hypothesis that a given factor does not influence reactor conversion was disregarded. While the model is indeed sensitive to pressure, the p-values associated with the pressure coefficients where greater than 0.05 . This indicates that although pressure does deterministically influence conversion in the model, the model is far less sensitive to reactor pressures than to temperature and feed ratio for the pressure ranges evaluated in the parametric analysis.

In Figure 4, the ratio of $\mathrm{H}_{2}: \mathrm{CO}_{2}$ molar feed dramatically influences the percent conversion of carbon dioxide as indicated by the separate surfaces generated with the regression model. The bottom surface is associated with a $\mathrm{H}_{2}: \mathrm{CO}_{2}$ molar feed of 1.0. In this case, the $\mathrm{CO}_{2}$ reduction reaction is hydrogen-limited and conversion is poor. The middle surface is associated with a ratio of 2 . Based on reaction stoichiometry, this value would be the optimum if the Bosch reaction did not proceed according to the sub reactions illustrated in equations (1-6). The top surface is associated with the ratio of 3 which shows increased conversion indicating that additional hydrogen is required to completely react all of the carbon dioxide that enters the recycle loop of the series-Bosch system. 
In addition to generating surface plots, the multivariate regression model can be used for optimization. In particular, the model regresses the 5 factors in the parametric analysis to a second order polynomial. Identifying the factors (RWGS pressure, RWGS temperature, CFr pressure, CFr temperature, and feed ratio) as $\phi_{k}$ for $k=1, \ldots, 5$, the regression model takes the following form.

$$
\text { Conversion(\%) }=\alpha+\sum_{k} \beta_{1, k} \phi_{k+} \beta_{2, k} \phi_{k}^{2}
$$

With the explicit 11-term expression for conversion percentage, optimization can now be performed. An objective function, $f$, was defined in which a minimum was sought using the Nelder-Mead downhill simplex method.

$$
f=\left[-100+\alpha+\sum_{k} \beta_{1, k} \phi_{k+} \beta_{2, k} \phi_{k}^{2}\right]^{2}
$$

Using the simplex method, the optimization routine predicted a minimum for $f$ (associated with a conversion percentage near $100 \%$ ) with a feed ratio of 2.923 and reactor temperatures of $888.0{ }^{\circ} \mathrm{C}$ for the RWGS and $360.0^{\circ} \mathrm{C}$ for the CFR. The temperature values were somewhat unexpected based on previous reactor component-level optimization without recycle streams. Moreover, these results are outside of the bounds in which the regression model was established. Consequently, this result requires verification with the model. However, these temperature values are a large excursion from what the model was established with, meaning the model needs to be run incrementally along an optimization path to arrive at the desired temperature settings. These results are in the right panel of Figure 4. The four dimensional plot indicates the values of reactor temperatures and feed ratio on the $x, y$, and $z$ axes. The fourth dimension, conversion percentage, is indicated in the marker color intensity ranging from 64.3-97.3\%. Consequently, even though the regression model was employing extrapolation, the model still seemed capable of predicting an optimum for $\mathrm{CO}_{2}$ conversion in this case. Consequently, the system model and optimization routines provide a powerful tool for reactor system design.

With the high temperature requirement for the RWGS predicted by the model, additional practical considerations need to be addressed including whether a heater can be sized and incorporated into the system given space limitations and whether or not the high temperatures can cause damage to downstream components such as the diaphragms within the compressor. These factors will continue to be addressed in the design stage. From a modeling standpoint, the unconstrained optimization technique can be modified to include terms such as a maximum allowable compressor temperature value. However, this analysis demonstrates the power of system model and regression techniques.

\section{B. Reverse Water-Gas Shift Sub-System Modeling Results}

The RWGS sub-system modeling effort was completed in phases. The first phase of the effort focused on simulating laboratory-scale dimensions, allowing verification of the model before scaling to a larger RWGS sub-system. The second phase of the effort focused on modeling a full-scale RWGS sub-system to explore the general performance. The final phase of the effort attempted to optimize the full-scale RWGS subsystem to facilitate sizing and other design considerations.

\section{Simulations at Laboratory-Scale Dimensions}

The first simulations with the computational model were for systems with dimensions and conditions comparable to the existing experimental system, for the purpose of validating

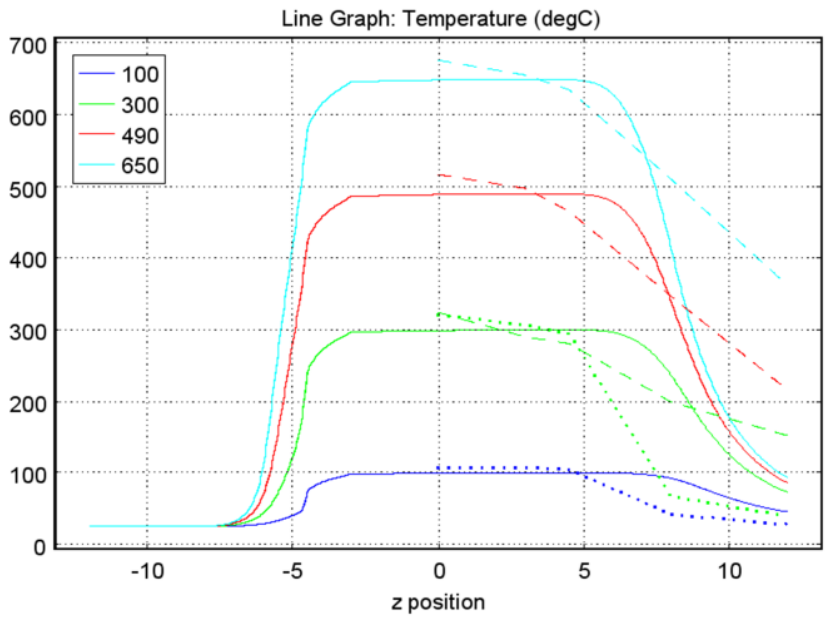

Figure 5. Experimental and computational centerline temperatures for various furnace setpoints. The color of each line corresponds to the furnace temperatures (in Celsius) shown in the legend. Solid lines show computational data. Dashed lines show experimental data with insulated tubes, and dotted lines show experimental data for non-insulated tubes. Z-position is shown in inches from center. the model against experimental data. The quartz reactor tube was given a length of $61 \mathrm{~cm}$ (24 inches), with an inner diameter of $4.6 \mathrm{~cm}$ (1.81 in) and wall thickness of $0.05 \mathrm{~cm}(0.02 \mathrm{in})$. The $30.5 \mathrm{~cm}$ (12 in) length in the middle of the tube was exposed to the hot furnace air at the 
outer wall boundary. On either side of this section was a $5 \mathrm{~cm}$ ( 2 in) long insulated boundary (corresponding to the insulation at the furnace ends), with the remaining $10 \mathrm{~cm}(4 \mathrm{in})$ at each end of the tube exposed to the cool ambient air. The catalyst length was $15 \mathrm{~cm}(6 \mathrm{in})$, and the quartz insulation disks were each $3.8 \mathrm{~cm}(1.5 \mathrm{in})$ long. The convection heat transfer coefficients between the tube wall and the air in the furnace and ambient were calculated from the Grashof number and assigned a value of $7.188 \mathrm{~W} / \mathrm{m}^{2} \mathrm{~K}$.

One set of simulations was intended to validate the heat transfer models. For these tests, the inlet gas flow consisted of $0.5 \mathrm{SLPM}$ of non-reacting $\mathrm{CO}_{2}$ entering at $25^{\circ} \mathrm{C}$ and 1.01325 bar. The ambient air temperature was set to $25^{\circ} \mathrm{C}$ at $1.01325 \mathrm{bar}$ pressure. Simulations were performed with the furnace temperature set to $100,300,490$, and $650^{\circ} \mathrm{C}$, all at 1.01325 bar pressure. The reactor centerline $(\mathrm{r}=0)$ temperature distributions of these simulations are presented in Figure 5 along with experimental measurements at locations from the center of the catalyst $(z=0)$ to the exit of the tube $(\mathrm{z}=12)$. The experimental measurements for $100^{\circ} \mathrm{C}$ were for a non-insulated tube, the measurements for $490^{\circ} \mathrm{C}$ and $650^{\circ} \mathrm{C}$ were for a tube with insulation from the furnace exit to the end of the tube, and
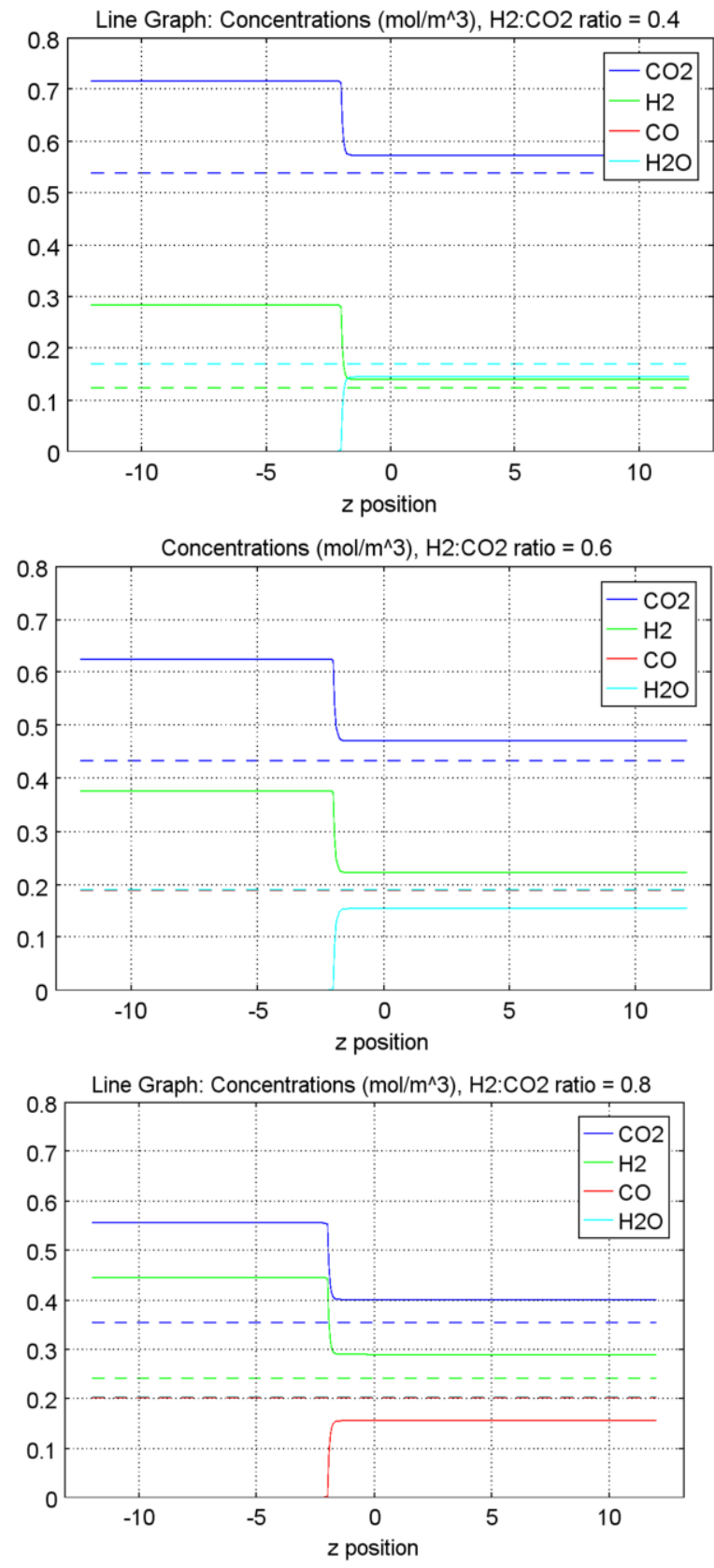

Figure 6. Axial species concentrations for different inlet $\mathbf{H}_{2}: \mathbf{C O}_{2}$ ratios. Solid lines show computational data. Dashed lines show exit concentrations from experimental tests. Color indicates species. The $\mathrm{CO}$ and $\mathrm{H}_{2} \mathrm{O}$ curves overlap. the measurements for $300^{\circ} \mathrm{C}$ included both insulated and non-insulated cases. The model shows temperature elevations that are localized around the furnace and very uniform within the furnace area. Gas entering the heated area is warmed to the furnace temperature over a relatively short distance, keeps a consistent temperature throughout the furnace area, and quickly cools after leaving the furnace. The experimental and computational temperature curves are generally similar, though there are some differences in the experimental trends. The experimental data shows a temperature distribution that is less uniform within the furnace, and rapid cooling of the exiting gases starting earlier in the experimental data - before the gas fully exits the furnace. Both of these trends suggest an air leak near the furnace exit that allows cooler ambient air into the heated area. However, in general there is good agreement between the experimental and computational trends, suggesting that the model captures the essential elements of the heat transfer.

Additional simulations were performed to test the chemistry models. The catalyst length was set to 10 $\mathrm{cm}$ (4 in). The temperatures of the furnace air and ambient air were $650^{\circ} \mathrm{C}$ and $25^{\circ} \mathrm{C}$, respectively, at a pressure of 1.01325 bar. The inlet gas stream consisted of well-mixed $\mathrm{H}_{2}$ and $\mathrm{CO}_{2}$ entering at $25^{\circ} \mathrm{C}$ and 1.01325 bar pressure, with a total flow rate of 0.18 SLPM. Simulations were performed with the inlet $\mathrm{H}_{2}: \mathrm{CO}_{2}$ ratio set to $0.4,0.6$, and 0.8 .

The results of the simulations are presented with the experimental concentration levels at the exit in Figure 6. The model results show a very rapid progression to equilibrium upon entering the catalyst region. The model shows the expected final concentrations from equilibrium data for this reaction. In the experimental case, however, the consumption of reactants is greater than what would be expected in an equilibrium case. A small degree of uncertainty is inherent in the experimental data. Even so, the progression of the experimental reactions past the expected equilibrium, combined with the detection of trace amounts of methane, raises the possibility of secondary reactions not

autics and Astronautics 
captured by the model, which only includes chemistry for the RWGS. The small discrepancies suggest that these effects are minor, however. On the whole, the computational results show a good degree of agreement with the experimental data and theoretical predictions of equilibrium composition.

\section{Full-Scale RWGS Sub-System Behavior}

With the validation tests complete, we next performed simulations of a full-scale reactor. The intent of these tests was to gain insight into trends in the fluid mechanics, heat transfer, and chemistry of the system, and to determine what aspects of the design might need to be revised for larger scales. At full scale, the reactor is estimated to have an inlet flow of 1.412 SLPM of $\mathrm{H}_{2}$ and 3.295 SLPM of $\mathrm{CO}_{2}$, or double these values with flow recycling. For these tests, only the inlet gas stream was changed; the dimensions and external conditions of the system remained the same as in the laboratory scale system, with a $15 \mathrm{~cm}\left(6\right.$ in) catalyst length and $650^{\circ} \mathrm{C}$ furnace temperature. The inlet gas stream was set up with the properties needed for full-scale operation with recycling: a temperature of $25^{\circ} \mathrm{C}$, a reduced pressure of 0.207 bar ( $3.1 \mathrm{psi}$ ), and a well-mixed flow consisting of 2.824 SLPM of $\mathrm{H}_{2}$ and 6.590 SLPM of $\mathrm{CO}_{2}$.

Figure 7 shows the velocity distribution in the gas stream. The open

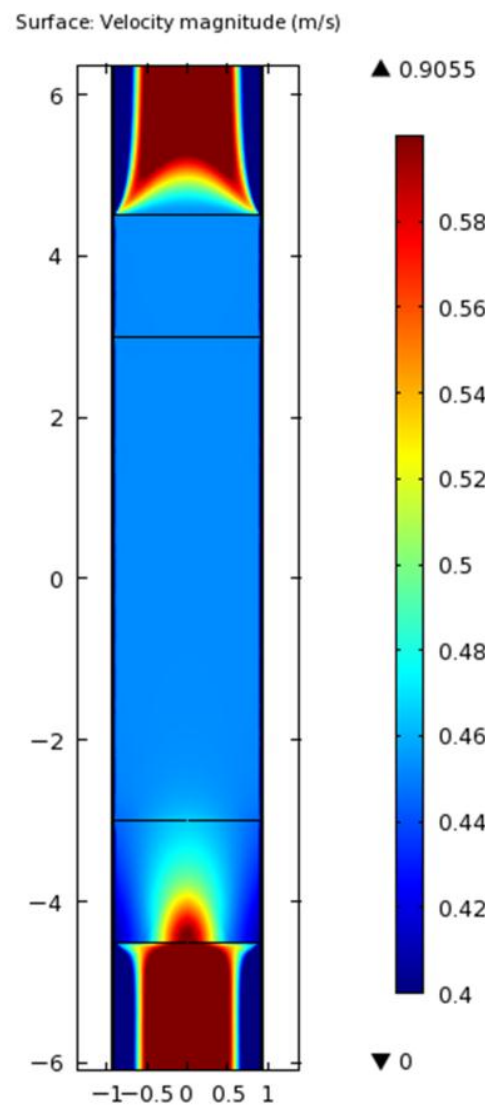

Figure 8. Velocity magnitudes in and around the porous region. The color range has been adjusted to highlight the region of transition in the porous insulation.

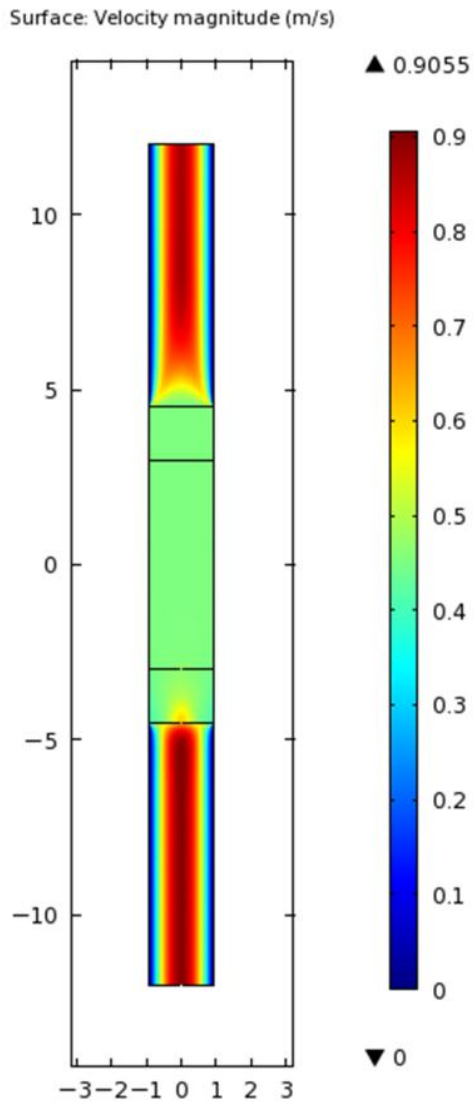

Figure 7. Velocity magnitudes throughout the system. Values along the vertical axis indicate the axial $(z)$ position along the reactor. Values along the horizontal axis indicate the radial ( $r$ ) position across the reactor. distribution as it enters the quartz insulation disk, but this distribution is smoothed out considerably as it progresses through to the catalyst. Placing even a small amount of porous material such as this one upstream of the catalyst helps to provide a much more uniform distribution of velocities for the catalyst section.

Figure 9 shows the temperature distribution in the system. The existing furnace setup is effective at heating the catalyst region, but the temperature elevation is somewhat localized to that area. In the upstream region, heating occurs only near the walls prior to the porous region. Downstream of the furnace, the flow is cooled rapidly through convective losses to the wall and ambient air. Within the porous region, however, the temperature is much more uniform, due in large part to the high thermal conductivity of the nickel catalyst, which facilitates the transfer of enthalpy from the hot walls to all parts of the fluid stream. The upstream quartz disk also contributes to this much as it did for the velocity profile, by promoting mixing between the hotter and cooler portions of the flow.

\section{Full-Scale Sub-System Optimization}

Our last simulations with the COMSOL model were intended to identify optimum catalyst dimensions for a fullscale system. Ideally, the system should be designed such that the gas temperature in the catalyst has minimal 


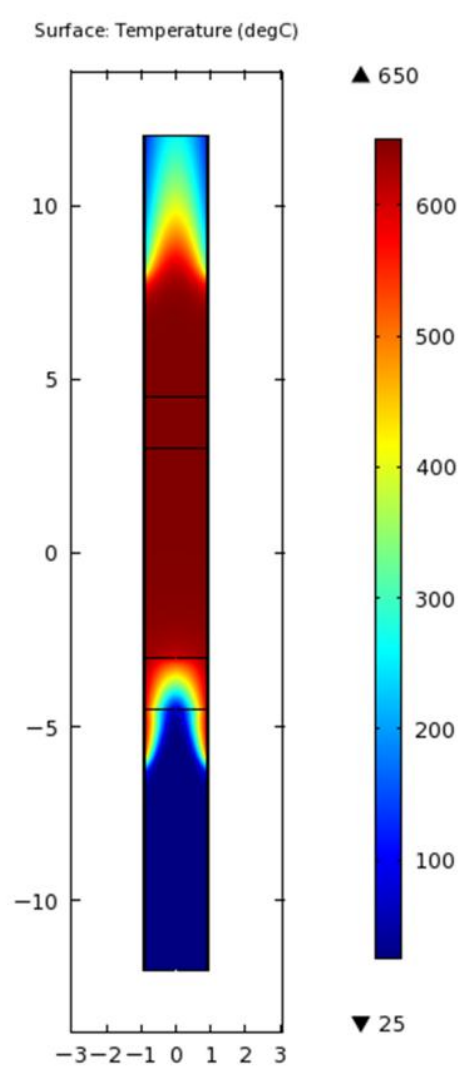

Figure 9. Temperature distribution inside full-scale reactor. variation, ensuring uniform reaction rates, and the residence time is sufficient to achieve the desired reaction completion throughout the flow. To this end, simulations were performed with the same basic design for the system, but with varying dimensions for the catalyst length and diameter. Computational experiments showed that the length of the catalyst section had little effect on the curvature of the concentration plots, instead affecting only how far the curves progressed toward equilibrium. This is primarily because the high thermal conductivity of the catalyst limits temperature variations along the catalyst length, so that changing the length will affect the residence time but not the reaction rate. Catalyst diameter, on the other hand, affects both the residence time and the distance from the heat source to the catalyst center, impacting both the reaction rate and the ultimate progression toward equilibrium. For this reason, the results presented here focus on the effects of diameter variation on the system performance. Basic conditions for these tests are the same as those in the previous large-scale system test. Two inlet flows were examined: the basic full-scale flow rates of 1.412 SLPM of $\mathrm{H}_{2}$ and 3.295 SLPM of $\mathrm{CO}_{2}$, and the flow rates with recycling of 2.824 SLPM of $\mathrm{H}_{2}$ and $6.590 \mathrm{SLPM}$ of $\mathrm{CO}_{2}$. The catalyst length was set to $20 \mathrm{~cm}$ ( 8 in) for all cases, and the diameter was examined for sizes ranging from the original value of $4.6 \mathrm{~cm}$ (1.81 in) up to $25.4 \mathrm{~cm}$ (10 in).

Figure 10 shows the radial temperature distribution at the upstream edge (or entrance) of the catalyst. Since at this point the gas stream has had the least time to receive heat from the warm walls and catalyst, this point represents the worst case for temperature distribution, with all downstream portions being more radially uniform. The temperature at the centerline is the lowest since it is farthest from the warm walls, while nearer the walls the temperature approaches the value for the furnace. As expected, larger diameters increase the distance between the centerline and the hot walls, thereby depressing the centerline temperature and making the distribution less uniform. However, since the catalyst has high thermal conductivity, the

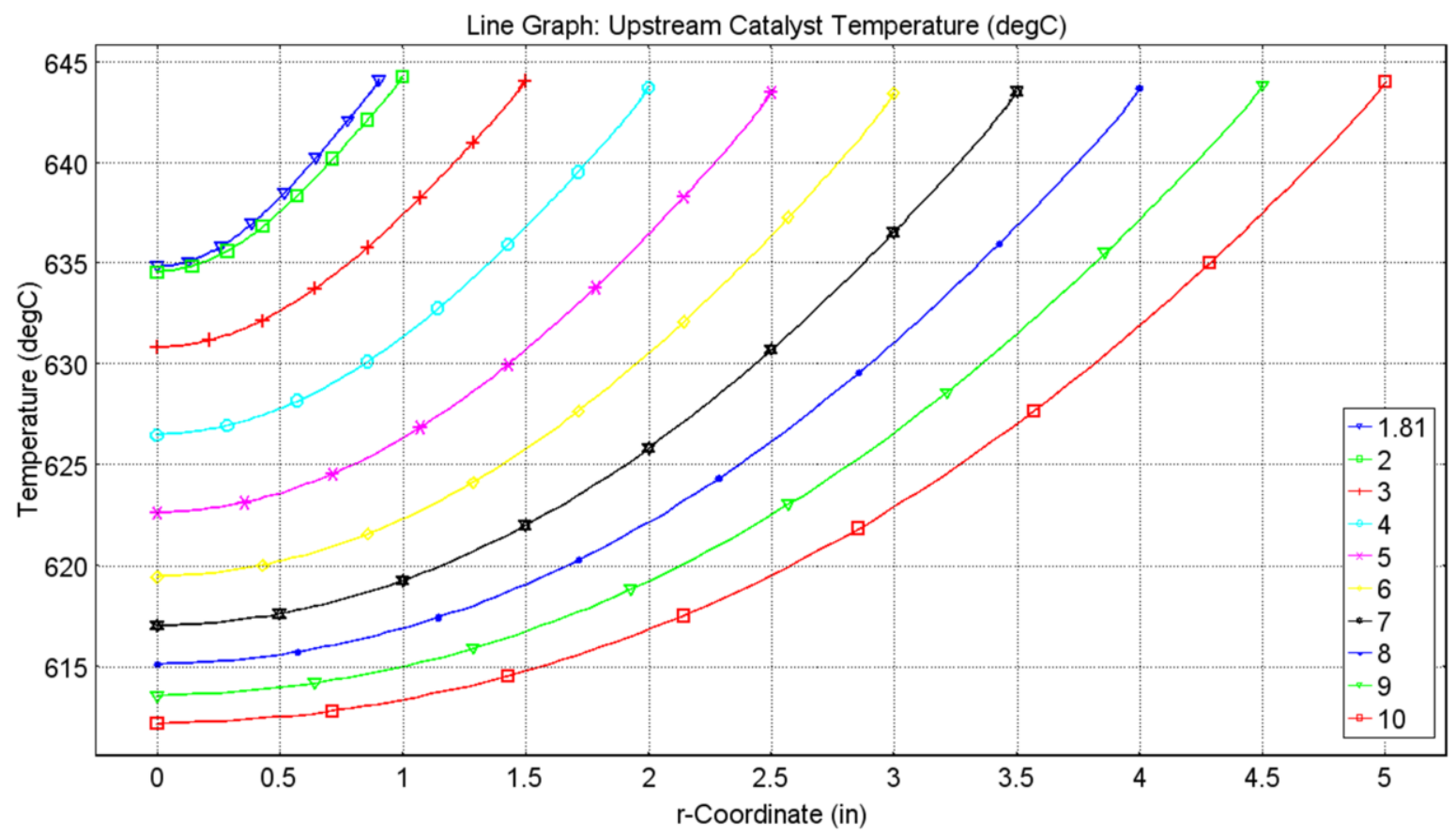

Figure 10. Radial temperature distribution at the inlet face of the catalyst for a full-scale system without recycle. The legend indicates the catalyst and tube diameter for each curve in inches. 
effect is not very large. Even at the largest diameter of $25.4 \mathrm{~cm}$ (10 in), the radial variation in absolute temperature is less than 5\%. Moreover, the temperature distribution downstream only becomes more uniform as the gas receives direct heating from the catalyst.

Figure 11 shows the concentration of $\mathrm{CO}_{2}$ along the centerline of the catalyst, which provides a gauge of reaction completion. Since the centerline should have the coolest temperatures and lowest reaction rates, this too provides a worst case view of reaction completion. As the plot shows, several of the larger diameters approach equilibrium by the end of the $20 \mathrm{~cm}(8 \mathrm{in})$ catalyst length, while diameters smaller than $12.7 \mathrm{~cm}(5 \mathrm{in})$ fall short. With little temperature variation within the catalyst, the degree of reaction completion is primarily a function of the residence time. Larger tubes decrease the flow speed and lengthen the residence time, though the same effect can be achieved with a longer catalyst. As little as $10 \mathrm{~cm}(4 \mathrm{in})$ of catalyst is sufficient for some of the largest diameters, while a 12.7 $\mathrm{cm}(5$ in) diameter needs a full $20 \mathrm{~cm}$ (8 in) of length. In principle a long enough catalyst would allow even the smaller diameters to reach equilibrium, though this would also require lengthening the furnace. With the existing equipment, a $12.7 \mathrm{~cm}$ ( 5 in) diameter tube and catalyst should be sufficient to achieve the desired level of reaction completion for a basic full-scale system.

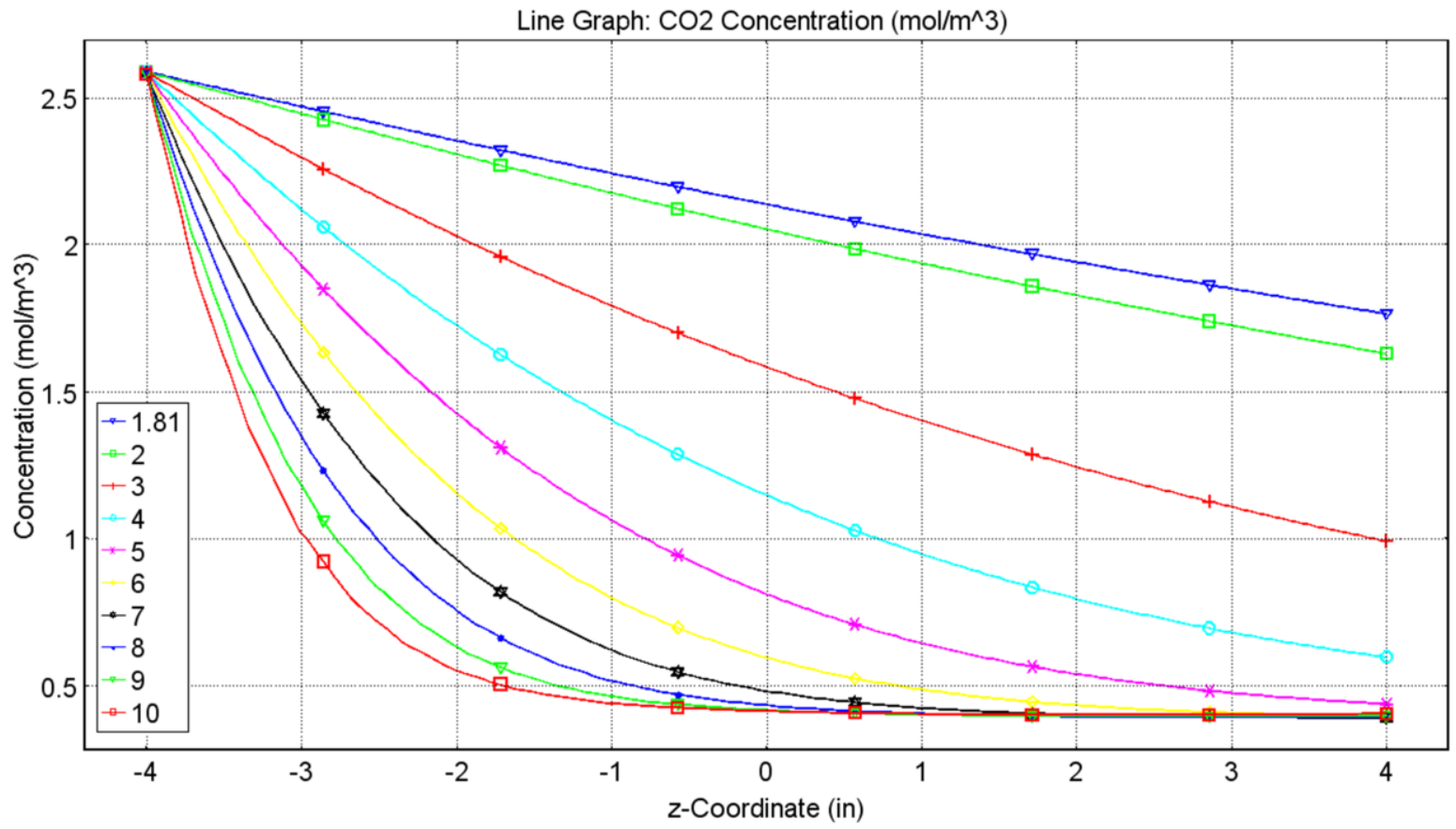

Figure 11. Axial $\mathrm{CO} 2$ concentrations along the catalyst centerline $(\mathbf{r}=\mathbf{0})$ for a full-scale system without recycling. The legend indicates the catalyst and tube diameter for each curve in inches.

Figure 12 and Figure 13 show results for the recycling system. The general trends are similar, though the higher flow rates make this case even more demanding. Interestingly, the smallest diameters produced the worst temperature uniformity. The reason for this is that the velocity is so high in these small tubes that the insulation material is not sufficient to fully mix and even out the flow distribution before the gas reaches the catalyst. As a result, at the upstream edge of the catalyst the centerline receives much cooler and faster-moving fluid, while near the wall the gas stream is slower and warmer due to preheating by the warm walls. This makes the radial temperature distribution much less uniform. A longer insulation section could potentially resolve this issue, and for diameters of at least $10 \mathrm{~cm}$ (4 in) the flow speed is slow enough that the existing insulation is sufficient to limit the velocity distribution at the catalyst entrance. At this point, the temperature distributions are not much worse than in the non-recycling case. The demands of a doubled flow rate make chemical equilibrium more difficult to achieve as well, as seen in Figure 13. The trends in the concentration profiles are essentially the same as for the non-recycling case, but a larger diameter of at least $20 \mathrm{~cm}$ ( 8 in) is needed to approach equilibrium by the end of the catalyst. 


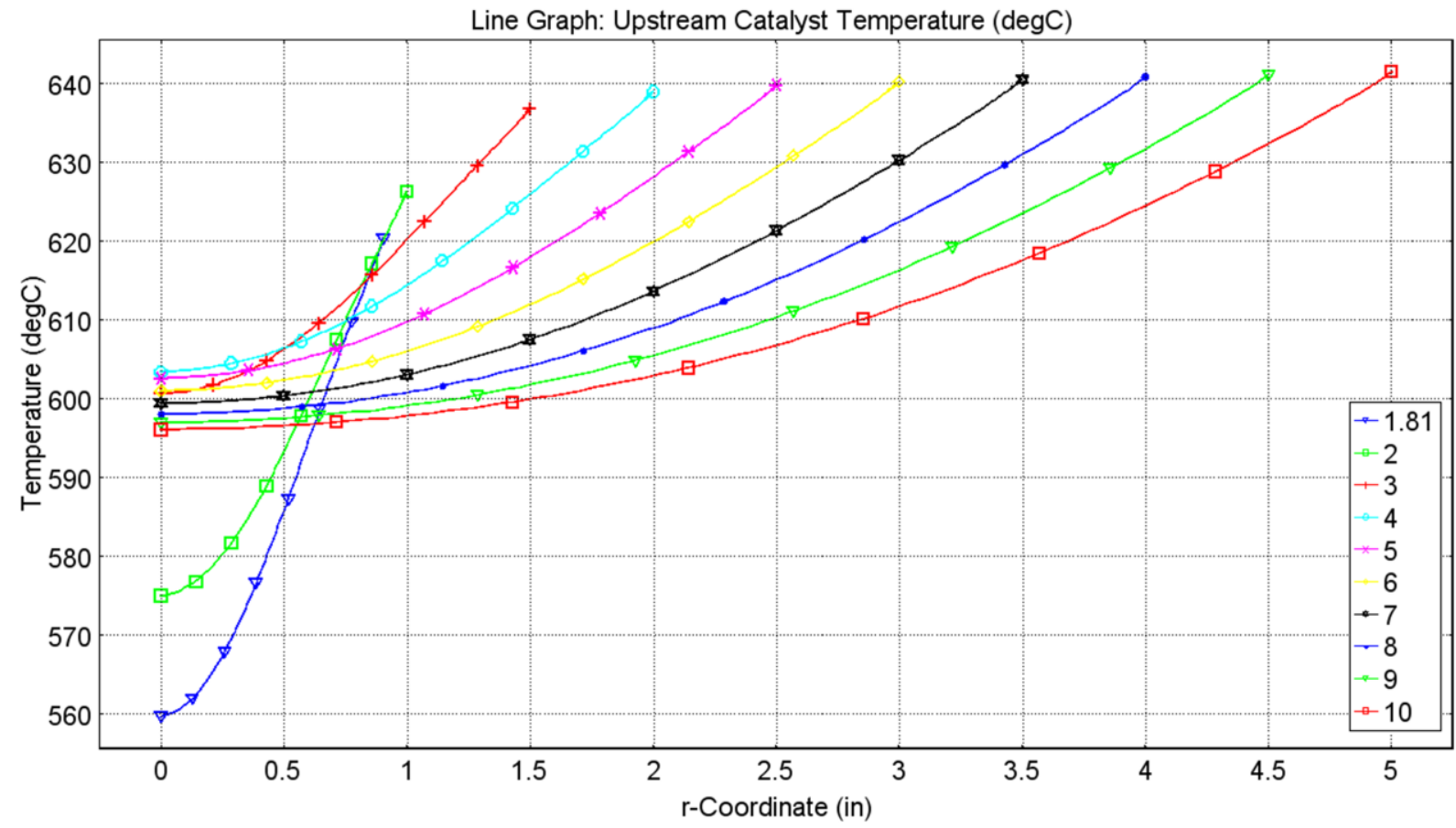

Figure 12. Radial temperature distribution at the inlet face of the catalyst for a full-scale system with recycling. The legend indicates the catalyst and tube diameter for each curve in inches.

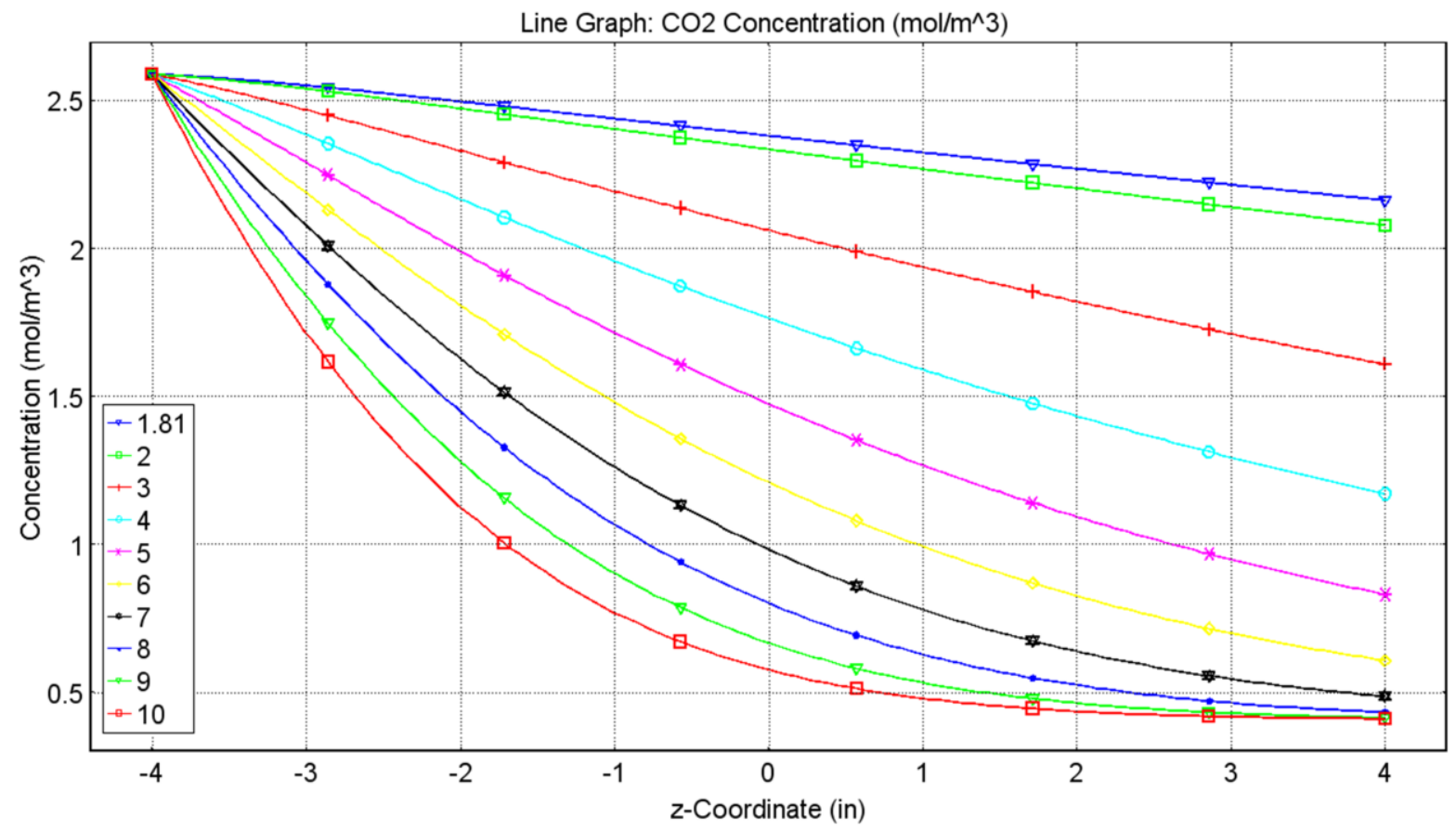

Figure 13. Axial $\mathrm{CO} 2$ concentrations along the catalyst centerline $(\mathbf{r}=\mathbf{0})$ for a full-scale system with recycling. The legend indicates the catalyst and tube diameter for each curve in inches. 


\section{Conclusions}

A steady-state equilibrium system model has been established for the Series-Bosch Reactor System. The model accepts reactor temperature, pressure, and feed composition inputs among a number of other parameters. Consequently, large-scale parametric analyses were performed for reactor optimization. As an example, temperatures and feed ratios were employed as inputs for the parametric analysis described in this work. A multivariate regression model was subsequently generated from the parametric analysis results to predict $\mathrm{CO}_{2}$ conversion. Unconstrained Nelder-Mead optimization was performed with the regression model in order to maximize percent conversion. The regression model predicted reasonable values for temperatures and feed ratio albeit the temperatures were outside of the bounds used to generate the model. Consequently, a verification study was performed to assess and confirm that the regression and system models were in agreement.

A COMSOL-based RWGS model was established to facilitate full-scale sub-system design for Series-Bosch system. The model varied temperature, pressure, length, and diameter in an attempt to optimize a reactor for operation both with and without gas recycle. The model suggested that diameter was a much more influential parameter than length for approaching thermodynamic equilibrium. Additionally, a design involving quartz insulation at the inlet of the reactor provides the benefit of flow distribution prior to entrance into the catalyst.

While results from the unconstrained optimization studies were encouraging, practical considerations need to be evaluated prior to acceptance of the results. This work is ongoing and will likely require optimization constraints associated with specific hardware requirements.

\section{Acknowledgments}

The authors would like to acknowledge the Office of the Chief Technologist Next Generation Life Support Project for funding this effort. Additional acknowledgements include Dave Long and Lee Miller for engineering support.

\section{References}

\footnotetext{
${ }^{1}$ Abney, M. B., Miller, L., and Williams, T., "Sabatier Reactor System Integration with Microwave Plasma Methane Pyrolysis Post-Processor for Closed-Loop Hydrogen Recovery," AIAA International Conference on Environmental Systems, AIAA-20106274, Barcelona, Spain, July 11-15, 2010.

${ }^{2}$ Carrasquillo, R. L., Carter, D. L., Holder, D. W., McGriff, C. F., and Ogle K. Y., "Space Station Freedom Environmental Control and Life Support System Regenerative Subsystem Selection," NASA Technical Memorandum 4340, Marshall Space Flight Center, 1992.

3 Abney, M.B., Mansell, J.M., "Evaluation of Bosch-Based Systems Using Non-Traditional Catalysts at Reduced Temperatures," AIAA International Conference on Environmental Systems, AIAA-2011-5059, Portland, OR, July 17-21, 2011.

${ }^{4}$ Green, D., and Perry, R., Perry's Chemical Engineers Handbook, Vol. 8, McGraw-Hill, 2008.

${ }^{5}$ Fogler, H., Vennema, A., and Vennema, C., Elements of chemical reaction engineering, Prentice-Hall Englewood Cliffs, NJ, 1992..

${ }^{6}$ Rawlings, J., and Ekerdt, J., Chemical reactor analysis and design fundamentals, Nob Hill Publishing, Madison, WI, 2002.
} 